\title{
Simulation as a component of introductory physiotherapy clinical placements
}

\author{
Catherine L Johnston $P h D$ \\ Senior Lecturer, Discipline of Physiotherapy, School of Health Sciences, The University of Newcastle, Callaghan, NSW, Australia
}

Jake C Wilson BPhysio (Hons)

Discipline of Physiotherapy, School of Health Sciences, The University of Newcastle, Callaghan, NSW, Australia

Luke Wakely $P h D$

Lecturer in Physiotherapy, The University of Newcastle Department of Rural Health, Tamworth, NSW, Australia

Sarah Walmsley $P h D$

Lecturer, Discipline of Physiotherapy, School of Health Sciences, The University of Newcastle, Callaghan, NSW, Australia

Clint J Newstead BPhysio (Hons)

Lecturer, Discipline of Physiotherapy, School of Community Health, Charles Sturt University, Orange, NSW, Australia

\section{ABSTRACT}

Simulated learning experiences (SLEs) assist students to acquire knowledge and skills and are an effective teaching tool in physiotherapy education. The aim of this project was to explore physiotherapy student attitudes towards SLEs as a preparatory component of an introductory clinical placement. The project was a quasi-experimental, pre/post-test repeated measures design. Participants were second year physiotherapy students $(n=57)$ allocated to a placement which included one week of SLEs and three weeks in a healthcare setting. The SLE week consisted of sessions to develop students' clinical skills in preparation for placement. Data on participant attitudes towards SLEs were collected via anonymous survey before and after the SLE week, and at the completion of the three week clinical placement. Attitudes of respondents $(n=43)$ towards SLEs were significantly more positive at the completion of the SLE week. At the completion of the three week clinical placement, all responses remained more positive than at the commencement of the project, however participant responses were generally less positive than at the conclusion of the week of SLEs. Students valued the use of SLEs in preparing for introductory clinical placements. Simulated learning experiences should be considered as a useful tool for pre-placement preparation for early year physiotherapy.

Johnston, C, L., Wilson, J, C., Wakely, L., Walmsley, S., Newstead, C, J. (2018). Simulation as a component of introductory physiotherapy clinical placements. New Zealand Journal of Physiotherapy 46(3): 95-104. doi:10.15619/NZJP/46.3.02

Key Words: Physical Therapy, Clinical Education, Simulation

Key Words: Physica Therapy, Cl,

\section{INTRODUCTION}

Clinical education in the discipline of physiotherapy refers to dedicated blocks of time where students are immersed in a healthcare setting to gain supervised experience (Lekkas et al., 2007). Clinical education is an important component of entrylevel physiotherapy programmes and it is a requirement that students complete a range of clinical placements to graduate as beginning level health practitioners (Crosbie et al, 2002; Lekkas et al., 2007; Stiller, Lynch, Phillips, \& Lambert, 2004). Clinical education enables students to consolidate and integrate knowledge gained in academic study and demonstrate the practical skills, attitudes and behaviours necessary for graduate professional practice (Higgs, 1992; Lindquist, Engardt, \& Richardson, 2004; McCallum, Mosher, Jacobson, Gallivan, \& Guiffre, 2013; Strohschein, Hagler, \& May, 2002).

Many physiotherapy programmes introduce students to clinical education in the early years of study. Early year clinical placements aim to provide an introduction to clinical practice and enable the development and demonstration of skills in clinical communication, professional behaviour, working in a multiprofessional team and managing non-complex patients. As students progress into their later years of study, clinical education placements and expectations become more complex and focus on the development of specific clinical expertise and higher order clinical reasoning skills.

The clinical education sphere is becoming increasingly more complex, in part, as a result of changes in the health-care and education sectors (Blackstock et al., 2013; Hall, Manns, \& Beaupre, 2015; McMeeken, Grant, Webb, Krause, \& Garnett, 2008). Students are expected to 'practise' in higher-risk environments as the medical complexity of patients increases, leading to concerns around patient and student safety (Blackstock et al., 2013). Expanding numbers of entry-level physiotherapy programmes have resulted in an overall increase in student numbers (Hall et al., 2015; McMeeken et al., 2008). Healthcare services' limited capacity to accommodate this increased demand may translate into fewer clinical education opportunities for students. To address these challenges, new models of clinical education, which prepare students to enter challenging clinical environments and ensure students have the required knowledge and skills to maximise available learning 
experiences, need to be developed. One such model currently being explored in physiotherapy is the integration of simulated learning experiences (SLEs) into traditional clinical education programmes (Blackstock et al., 2013).

Simulated learning experiences are used in healthcare professional education to replicate aspects of real clinical practice and enhance student learning (Gaba, 2004; May, Park, \& Lee, 2009; Weller, Nestell, Marshall, Brooks, \& Conn, 2012). In healthcare, there have been various forms of SLEs developed and used with varying levels of fidelity, including cardiopulmonary resuscitation dummies, modelled body segments, technologically advanced full body mannequins and actors portraying patient roles (Blackstock \& Jull, 2007; Bradley, 2006; Gaba, 2004; May et al., 2009; Weller et al., 2012). High fidelity SLEs that involve patient actors known as simulated patients (SPs), are emerging as an effective teaching tool in physiotherapy education (Blackford, McAllister, \& Alison, 2015; Blackstock et al., 2013; Cahalin \& Markowski, 2011; Ladyshewsky \& Gotjamanos, 1997; Lewis, Bell, \& Ashgar, 2008; Pritchard, Blackstock, Nestell, \& Keating, 2016; Watson et al., 2012). The purpose of SLEs is to allow students to acquire, consolidate and implement knowledge and practical skills in a safe and supportive environment (Gaba, 2004; Kant \& Cooper, 2010; Lasater, 2007; Steadman et al., 2006; Weller et al., 2012). Simulated learning experiences also assist students to develop skills relating to communication, professional behaviour and teamwork (Pritchard et al., 2016; Weller et al., 2012).

Simulated learning experiences in physiotherapy have been used to improve student preparedness for clinical education and facilitate the acquisition of communication, team work and specific technical skills (Blackford et al., 2015; Blackstock et al., 2013; Ladyshewsky \& Gotjamanos, 1997; Lewis et al., 2008; Watson et al., 2012). Studies have shown that SLEs may replace traditional placement time without detriment to student attainment of clinical competencies, and enhance confidence levels (Blackstock et al., 2013; Watson et al., 2012). Research into the use of SLEs in physiotherapy clinical education has predominantly involved students in their later years of study, undertaking placements in specific clinical areas such as musculoskeletal outpatients or acute care. There is less evidence to support the effectiveness, or value, of SLEs as part of introductory clinical placements for early year physiotherapy students. Currently, the most applicable model of clinical education using simulated learning experiences for early year physiotherapy students is unknown. Research on the value of SLEs for early year students is needed so that useful and effective models of clinical education can be developed. The aim of this research project was to explore early year physiotherapy students' attitudes towards SLEs as a preparatory component of introductory clinical placement.

\section{METHODS}

\section{Study design}

The study was a quasi-experimental, pre and post-test repeated measures design. Ethics approval was granted for the study from the University of Newcastle Human Research Ethics Committee (reference number H-2014-0389).

\section{Setting}

The Bachelor of Physiotherapy (BPhysio) programme at the University of Newcastle (UON), Australia, is a four year undergraduate entry-level qualification. The programme includes a total of 29 weeks of clinical placement, completed across years two to four. There are 6 block placements and each constitutes a full stand-alone course (subject) with the clinical assessment making up the student's final grade. All second year physiotherapy students undertake an introductory four week full time clinical placement block. These introductory clinical placements are undertaken in various healthcare facilities including public and private hospitals, private practices, aged care and community settings. Students attend this placement with an educator to student ratio between $1: 1$ and $1: 6$ as is usual practice in physiotherapy clinical education in Australia. During these placements students are introduced to the role and practice of physiotherapy in the healthcare setting and have their own introductory clinical caseload. Students are responsible, under supervision, for managing patients across the lifespan with a range of medical conditions. They are expected to show basic clinical reasoning and to demonstrate assessment and treatment skills learned during their early years of university study.

Student performance on this introductory placement is assessed by the site clinical educator throughout the placement and formally at completion, using criteria adapted from the National Assessment of Physiotherapy Practice (APP) tool (Dalton, Davidson \& Keating, 2011; Dalton, Davidson \& Keating, 2012). Students are awarded a mark out of 80 which is converted to a grade out of 100 , and must achieve $50 \%$ to pass the course. Passing the placement course is a prerequisite for subsequent clinical placements and students are unable to progress through the physiotherapy programme if they do not successfully complete this introductory clinical placement.

\section{Participants and recruitment}

Participants were physiotherapy students enrolled in their second year of the BPhysio in 2014 and 2015. Participants in this study were those students allocated to a combined simulation-traditional placement as their second year clinical placement course. Physiotherapy students do not have the opportunity to choose their own clinical placements in second year, however they are permitted to submit preferences for the geographical location of their placement. Therefore in keeping with usual practice, all enrolled students were given all standard placement location options in which combined simulationtraditional placements were included. Students participating in this research project were then allocated to the combined simulation-traditional clinical placement as per the usual process for allocation of physiotherapy clinical placements.

All students who were allocated to the combined simulationtraditional placements $(n=57)$ were invited to participate in the research project and provided with participant information forms prior to the commencement of the project. There were no specific exclusion criteria.

\section{Intervention}

Between October 2014 and November 2015 a number of second year placements were modified to incorporate an initial 
week containing SLEs. Students undertaking these combined placements, instead of completing the usual four week full time clinical placement block, completed one week of SLEs (simulation component) immediately followed by three weeks of full time placement in a healthcare setting (clinical component)

The simulation component of the combined placement was undertaken in a specialised simulation centre with a ratio of one physiotherapy simulation educator to four students. The SLEs consisted of tutorials, practical sessions and interactions with simulated patients to develop students' clinical skills in preparation for placement including medical note reading, professional behaviour, communication, manual handling and simple assessment and interventions. Details of the content and structure of each day of the simulation week are contained in Table 1.

The simulation experience in this project was not intended to be a formal 'standardised' experience, therefore strictly scripted scenarios were not required. Simple clinical scenarios which replicated cases likely to be encountered by second year students during the full time clinical placement weeks (joint arthroplasties, mechanical falls and basic respiratory conditions) were developed by two experienced physiotherapists formally trained in the use of SLEs. Simulated patients (SP) were sourced from a database of trained actors through the University medical school. Prior to the placement, the actors familiarised themselves with the clinical scenarios and were given individual training by the simulation educator.

The student interactions with the SPs included practising patient history taking, physical assessment, simple treatments such as joint range of motion and strengthening exercises, gait and mobility assessment and intervention, and general manual handling skills. The simulation educators were able to 'pause' the interaction at any time to give students on-thespot feedback. After each scenario was completed, the SPs were instructed to break character and give students individual feedback about their communication, professional behavior and/ or manual handling skills during the interactions. Debriefing occurred at the conclusion of each day of simulation (Fanning \& Gaba, 2007).

\section{Table 1: Content and structure of the simulation week}

\begin{tabular}{lll}
\hline Day & Focus & Content and structure \\
\hline 1 & i) Introduction and orientation & Orientation and introduction \\
ii) Professional behaviour & Interactive small group tutorial/practical: \\
& - Professional behaviour \\
& - Familiarisation with medical notes \\
& - Practice gathering and summarising a patient's medical history
\end{tabular}

i) Delivering a verbal handover and communicating with clinical educator

iii) Preparation for patient history taking

3

i) Patient history taking

ii) Preparation for physical examination and assessment

i) Physical examination and assessment

ii) Preparation for treatment implementation and manual handling

5

i) Treatment implementation and manual handling

ii) Preparation for traditional immersion clinical placement
Practice delivering a verbal handover Interactive small group tutorial/practical:

- Clinical communication and history taking

- Planning a subjective history

- Preparation for engagement with Simulated Patients (SPs)

History taking practice with SPs

Feedback and debrief session

Interactive small group tutorial/practical:

- Use of medical equipment (eg beds and wall attachments)

- Planning assessment/physical examination

Physical assessment practice with SPs

Feedback and debrief

Interactive small group tutorial/practical:

- Treatment planning and implementation

- Manual handling

Basic treatment and manual handling practice with SPS

Feedback and debrief

Interactive small group session:

- Preparation for entering the traditional clinical placement setting

- Question and answer session 
Following the completion of the week-long simulation component, the students went on to complete three weeks of traditional clinical placement (clinical component) in a healthcare setting.

\section{Survey instrument and data collection process}

There was no published survey instrument suitable for data collection in this study population, therefore a purpose designed survey was developed. The survey was intended to collect data on attitudes towards the use of SLEs in early year physiotherapy clinical education. The survey was developed by two experienced physiotherapists, trained in clinical education and simulation delivery.

The written survey consisted of 21 questions in two sections (see Appendix 1). Section one included general participant characteristics and section two canvassed general attitudes towards the use of SLEs as part of early year physiotherapy clinical education and their value in developing physiotherapy skills. Survey questions were mostly in closed categorical or five-point Likert scale form with a free text section provided for participants to add any additional comments.

Participants completed the survey at three time points: prior to the simulation component (Survey 1), at the conclusion of the simulation component (Survey 2) and at the completion of the subsequent three week clinical component (Survey 3). Details of the data collection process are displayed in figure 1.

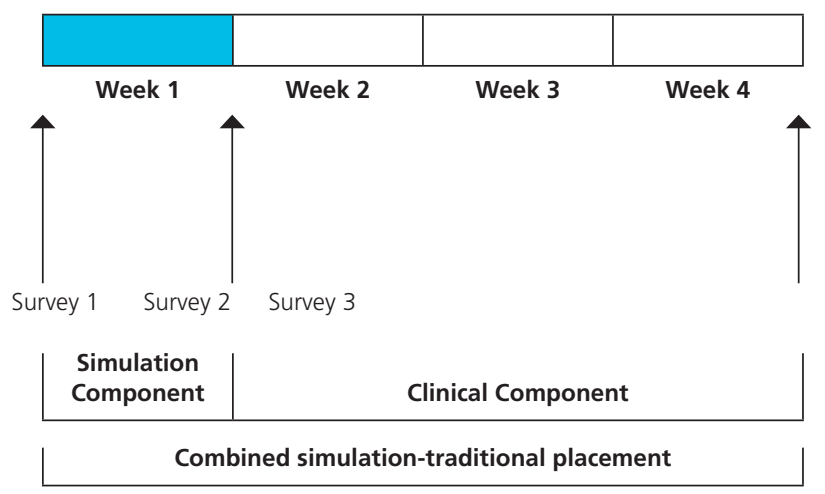

\section{Figure 1: Structure of the combined simulation-traditional placement and data collection process}

All surveys were completed anonymously and coded so that responses could be matched across the three time points. Individual responses could not be identified or matched to any participant at any stage of the study.

\section{Data analysis}

All data were collated and analysed using the SPSS software (version 23, SPSS Inc Chicago II.). Participant characteristics and Likert scale responses were all reported using descriptive statistics. Likert scale responses were assigned numerical scores for data analysis (1-5: strongly disagree, disagree, neutral, agree, strongly agree). Analysis involved the comparison of data from Survey 1 and Survey 2 (change following the simulation component) and from Survey 2 and Survey 3 (change following the clinical component). For each Likert scale question, a change score was calculated by subtracting the numerical score for question responses in survey 1 from that of survey 2 . The same process was used to calculate individual change scores between survey 2 and survey 3 . Change scores were analysed using the sign test to evaluate the occurrence of any significant directional shift (Roberson, Shema, Mundform \& Holmes, 1995).

\section{RESULTS}

Forty-three participants completed all three surveys. The mean age of respondents was 23 years (SD 6 years), 25 (58\%) were female and most ( $n=42,98 \%)$ had not previously participated in SLEs using SPs.

\section{Simulation Component}

General attitudes of respondents towards SLEs and their value in developing physiotherapy skills were significantly more positive at the completion of the simulation component of the combined placement. These results are presented in Tables 2 and 3.

\section{Clinical Component}

At the completion of the clinical component of the combined placement, all responses remained more positive than at the commencement of the project, however participant responses were generally less positive than at the conclusion of the simulation component (Tables 4 and 5).

\section{DISCUSSION}

The results of this study are an important addition to the growing body of literature related to the use of SLEs in physiotherapy clinical education. To our knowledge, this study is the first to evaluate early year students' attitudes towards SLEs as a preparatory component of an introductory clinical placement. The main findings of this study were that participants strongly valued the SLEs and perceived them as useful in assisting skill development and preparation for clinical placement. This study also found that participants placed slightly less value on the SLEs and their usefulness in some domains of practice after completing three weeks of a traditional clinical placement.

Prior to commencing the combined placement, participants' attitudes towards the use of simulation were largely neutral. The use of SLEs as a component of clinical education in physiotherapy programmes is relatively novel and this research marked the first occasion the University had modified physiotherapy clinical placements to incorporate SLEs. Students involved in this study had not previously participated in SLEs and were unfamiliar with the outcomes of similar projects. This may have resulted in some scepticism towards non-traditional modes of physiotherapy clinical education, including the use of SLEs.

Participant attitudes improved significantly after completing the week of SLEs, and they remained positive at the conclusion of the combined placement. The change in attitudes indicated that the participants valued the SLEs, and considered that they supported the development of knowledge and skills, and increased preparedness for practice in a clinical setting. This was achieved by the provision of an appropriate, well-structured, supportive and realistic simulated learning environment (Gaba, 2004; Issenberg, Mcgaghie, Petrusa, Gordon, \& Scalese, 2005). The positive student attitudes following the SLE component are consistent with other research findings of improvements in physiotherapy students' self-rated communication, patient 

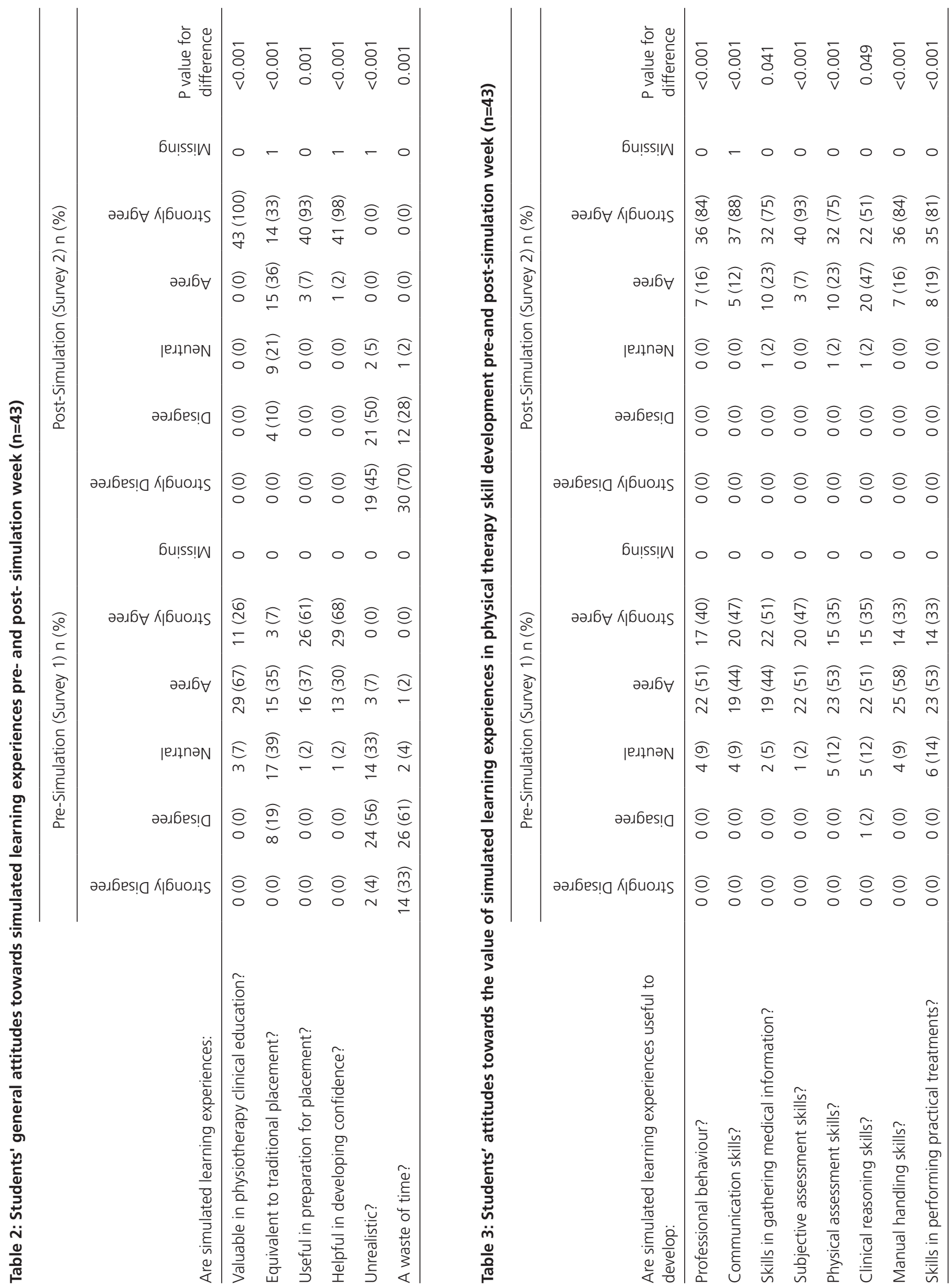


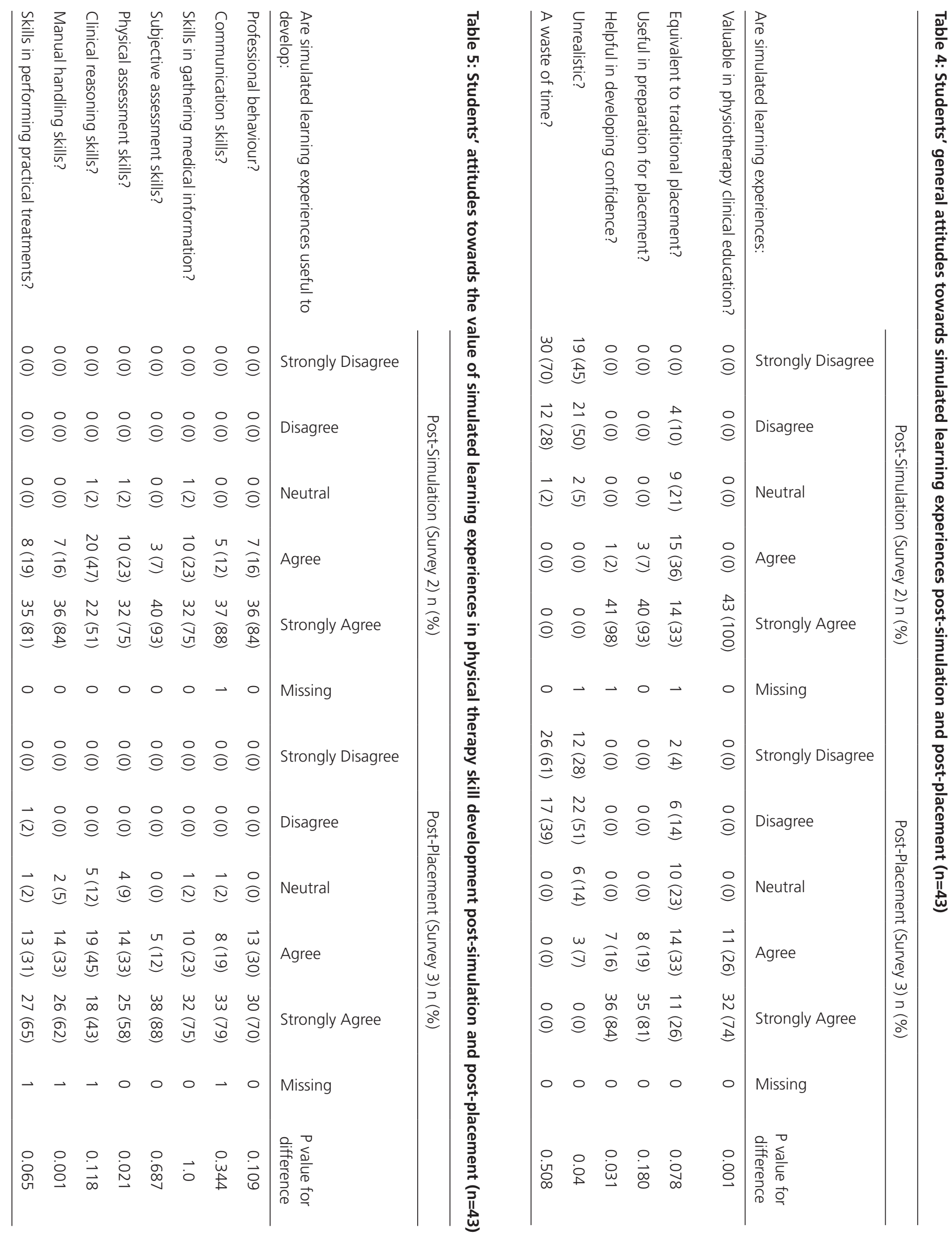


assessment and management following one week of SLES (Blackford et al., 2015; Blackstock et al., 2013; Watson et al., 2012). While not formally evaluated as part of this research project, the educators who supervised students who had undertaken the SLE placements also had very positive attitudes regarding the impact of the SLE component on the students' skills and preparedness.

While the SLEs were valued very highly at the conclusion of the simulation component, we found that participants' attitudes were slightly less positive at the completion of three weeks of traditional clinical placement. Although a high fidelity approach was used in this project, physiotherapy practice in a traditional clinical settings has other layers of complexity that cannot always be easily integrated into SLEs. During the time students spent immersed in a traditional setting, they were exposed to the realities of clinical practice, which may have impacted on the perceived value of the SLEs. Simulation is most beneficial when used in conjunction with clinical practice (Kneebone, Scott, Darzi, \& Horrocks, 2004) therefore, as the intended purpose was to prepare students for traditional clinical placement rather than to solely replace clinical time, the SLEs and the clinical placement weeks were integrated closely in this project.

In terms of specific clinical skills, students were less positive about the ability of the SLEs to prepare them for tasks such as patient handling, physical assessments and treatments following the three weeks of traditional placement. This is possibly because the SLEs were weighted more towards developing generic professional skills such as written and verbal communication, gathering medical information and professional behaviour. Medical simulation may be limited in its ability to entirely replicate the physical presentation of real patients and in physiotherapy, SLEs may be less suited for the development of certain domains of practice such as treatment and manual handling. Students did practise physical assessment, treatment and general manual handling skills during the simulation component, and had covered these skills in depth in their university coursework, however possibly more of these activities need to be included. Future research should be undertaken to explore the optimal structure and content of SLEs for students at this year level. Research should also include the objective measurement of student outcomes (such as the performance of manual skills) following participation in a placement involving SLEs and to compare those outcomes to similar students participating in a standard traditional placement. It would also be valuable to undertake a more in-depth qualitative exploration of early-year students' perceptions of the utility of SLE and to further investigate why these perceptions may change following immersion in the 'real' clinical environment.

The main limitations of this study were that the survey was self-reported, and was not formally validated. The survey content, however was informed by the current National Physiotherapy Practice Thresholds (The Physiotherapy Board of Australia, Physiotherapy Board of New Zealand, 2017) and based on the domains of the Assessment of Physiotherapy Practice tool (Dalton et al., 2011; Dalton et al., 2012). The survey was developed by two physiotherapists, experienced in clinical education research, and trained in simulation delivery using SPs and was reviewed by an independent physiotherapist with a background in clinical education. Further research to develop and validate a tool which can be used to collect data on attitudes towards the use of SLE is required.

Other limitations were the non-random allocation of participants and the lack of a comparison group. In addition, participants were students enrolled at one University in an undergraduate degree programme and the results may therefore not be generalisable to other physiotherapy programmes with different entry-level structures. Further research on the use of SLEs with early year students in other types of entry-level physiotherapy programmes, using larger sample sizes and including a comparison group, would be beneficial to evaluate the effectiveness of this intervention across populations.

\section{CONCLUSION}

This study demonstrated that early year physiotherapy students valued the use of SLEs as a preparatory component of a general introductory clinical placement. Students were most positive about the value of SLEs in assisting the development of their communication skills and professional behaviour. Students considered that participation in the combined placement equipped them to more confidently enter, and engage with, the traditional clinical placement setting. Simulated learning experiences, such as those used in this study, should be considered as a component of effective student preparation for placement and as a useful alternative model of clinical education for early year physiotherapy students.

\section{KEY POINTS}

1. Simulated learning experiences (SLEs) have been used to prepare physiotherapy students to safely practise in challenging clinical environments. However, research into the use of SLEs in physiotherapy clinical education has predominantly involved students in specific clinical areas (such as acute care) in their later years of study. The effectiveness and utility of using SLEs as part of introductory clinical placements for early year physiotherapy students is less clear. This study evaluated early-year physiotherapy students' attitudes towards an introductory clinical placement which included a preparatory week of simulated learning experiences.

2. Results of the study indicated that the participating students valued the SLEs and perceived them as useful in assisting their skill development and preparation for clinical placement. Interestingly the students' perceptions of the usefulness of the SLEs was slightly less positive, particularly in some domains of practice, after completing three weeks of a traditional clinical placement.

3. Simulated learning experiences should be considered as a component of effective early-year student preparation for placement and as a useful alternative model of clinical education for early year physiotherapy students.

\section{DISCLOSURES}

Funding to support the conduct of this study was received from the Mid North Coast Local Health District, New South Wales (NSW) Health Education Training Institute (HETI). The authors are not aware of any conflicts of interest requiring declaration. 


\section{PERMISSIONS}

Ethics approval was granted for the study from the University of Newcastle Human Research Ethics Committee (reference number H-2014-0389). All participants consented to participate.

\section{ADDRESS FOR CORRESPONDENCE}

Catherine L Johnston, Discipline of Physiotherapy, School of Health Sciences, The University of Newcastle, Callaghan, NSW, 2308, Australia. Telephone: +61 24921 7782. Email: cath. johnston@newcastle.edu.au.

\section{REFERENCES}

Blackford, J., McAllister, L., \& Alison, J. (2015). Simulated learning in the clinical education of novice physiotherapy students. International Journal of Practice-based Learning in Health and Social Care, 3, 7-93. doi:10.18552/ijpblhsc.v3i1.209.

Blackstock, F.C., \& Jull, G.A. (2007). High-fidelity patient simulation in physiotherapy education. Australian Journal of Physiotherapy, 53, 3-5. doi:10.1016/S0004-9514(07)70056-9.

Blackstock, F.C., Watson, K.M., Morris, N.R., Jones, A., Wright, A., McMeeken, J.M., ... Watson G. (2013). Simulation can contribute a part of cardiorespiratory physiotherapy clinical education: two randomised trials. Simulation in Healthcare, 8, 32-42. doi:10.1097/ SIH.0b013e318273101a

Bradley, P. (2006). The history of simulation in medical education and possible future directions. Medical Education, 40, 254-262. doi:10.1111 /j.1365-2929.2006.02394.

Cahalin, L.P., Markowski, A., Hickey M., Hayward, L. (2011). A cardiopulmonary instructor's perspective on a standardized patient experience: Implications for cardiopulmonary physical therapy education. Cardiopulmonary Physical Therapy Journal, 22(3), 21-30.

Cant, R.P., \& Cooper, S.J. (2010). Simulation-based learning in nurse education: Systematic review. Journal of Advanced Nursing, 66(1), 31-15. doi:10.1111/j.1365-2648.2009.05240.x.

Crosbie, J., Gass, E., Jull, G., Morris, M., Rivett, D., Ruston, S., ... Wright, T. (2002). Sustainable undergraduate education and professional competency. Australian Journal of Physiotherapy, 48(1), 5-7. doi:10.1016/ S0004-9514(14)60276-2

Dalton, M., Davidson, M., \& Keating, J. (2011). The Assessment of Physiotherapy Practice (APP) is a valid measure of professional competence of physiotherapy students: a cross-sectional study with Rasch analysis. Journal of Physiotherapy, 57, 239-246. doi:10.1016/S18369553(11)70054-6.

Dalton, M., Davidson, M., \& Keating, J. (2012). The assessment of physiotherapy practice (APP) is a reliable measure of professional competence of physiotherapy students: a reliability study. Journal of Physiotherapy, 58, 49-56. doi:10.1016/S1836-9553(12)70072-3.

Fanning, R.M., \& Gaba, D.M. (2007). The role of debriefing in simulationbased learning. Simulation in Healthcare, 2(2), 115-125. doi:10.1097/ $\mathrm{SIH} .0 \mathrm{~b} 013 \mathrm{e} 3180315539$

Gaba, D.M. (2004). The future vision of simulation in health care. Quality and Safety in Healthcare, 1, 2-10. doi:10.1136/qshc.2004.009878.

Hall, M., Manns, P., Beaupre, L. (2015). To supervise or not to supervise a physical therapist student: A national survey of Canadian physical therapists. Journal of Physical Therapy Education, 29(3), 58-67.

Higgs, J. (1992). Managing clinical education: The educator-manager and the self-directed learner. Physiotherapy, 78(11), 822-828. doi:10.1016/S00319406(10)60453-1.

Issenberg, B.S., Mcgaghie, W.C., Petrusa, E.R., Gordon, D.L., \& Scalese, R.J. (2005). Features and uses of high-fidelity medical simulations that lead to effective learning: a BEME systematic review. Medical Teacher, 27(1), 1028. doi:10.1080/01421590500046924
Kneebone, R.I., Scott, W., Darzi, A., \& Horrocks, M. (2004). Simulation and clinical practice: strengthening the relationship. Medical Education, 38, 1095-102. doi:10.1111/j.1365-2929.2004.01959.x.

Ladyshewsky, R., \& Gotjamanos, E. (1997). Communication skill development in health professional education: the use of standardised patients in combination with a peer assessment strategy. Journal of Allied Health, 26, 177-186.

Lasater, K. (2007). High-fidelity simulation and the development of clinical judgement: Students' experiences. Journal of Nursing Education, 46, 269276.

Lekkas, P., Larsen, T., Kumar, S., Grimmer, K., Nyland, L., Chipchase, L., .. Finch, J. (2007). No model of clinical education for physiotherapy students is superior to another: a systematic review. Australian Journal of Physiotherapy, 53(1), 19-28. doi:10.1016/S0004-9514(07)70058-2

Lewis, M., Bell, J., \& Asghar, A. (2008). Use of simulated patients in development of physiotherapy students' interpersonal skills. International Journal of Therapy and Rehabilitation, 15, 221-227. doi:10.12968/ ijtr.2008.15.5.29234.

Lindquist, I., Engardt, M., \& Richardson B. (2004). Early learning experiences valued by physiotherapy students. Learning in Health and Social Care, 3, 17-25. doi:10.1111/j.1473-6861.2004.00060.x

May, W., Park, J.H., \& Lee, J.P. (2009). A ten-year review of the literature on the use of standardised patients in teaching and learning: 1996-2005. Medical Teacher, 31, 487-492. doi:10.1080/01421590802530898.

McCallum, C.A., Mosher, P.D., Jacobson, P.J., Gallivan, S.P., \& Giuffre, S.M. (2013). Quality in physical therapist clinical education: A systematic review. Physical Therapy, 93(10), 1298-1311. doi:10.2522/ptj.20120410.

McMeeken, J., Grant, R., Webb, G., Krause, K.L., Garnett, R. (2008). Australian physiotherapy student intake is increasing and attrition remains lower than the university average: a demographic study. Australian Journal of Physiotherapy, 54(1), 65-71. doi:10.1016/S0004-9514(08)70068-0.

Physiotherapy Board of Australia, Physiotherapy Board of New Zealand. Physiotherapy practice thresholds in Australia and Aotearoa New Zealand. Retrieved from https://physiocouncil.com.au/wp-content/uploads/2017/10/ Physiotherapy-Board-Physiotherapy-practice-thresholds-in-Australia-andAotearoa-New-Zealand.pdf

Pritchard, S.A., Blackstock, F.C., \& Nestel, D., Keating, J.L. (2016). Simulated Patients in Physical Therapy Education: Systematic Review and MetaAnalysis. Physical Therapy, 96(9), 1342-1352. doi:10.2522/ptj.20150500

Roberson, P.K., Shema, S.J., Mundform, D.J., \& Holmes, T.M. (1995). Analysis of Paired Likert Data: How to Evaluate Change and Preference Questions. Family Medicine, 27(10), 671-675

Steadman, R.H., Coates, W.C., Huang, Y.M., Matevosian, R., Larmon, BR., McCullough, L., \& Ariel, D. (2006). Simulation based training is superior to problem based learning for the acquisition of critical assessment and management skills. Critical Care Medicine, 34,151-157. doi:10.1097/01. CCM.0000190619.42013.94

Stiller, K., Lynch, E., Phillips, A.C., \& Lambert, P. (2004). Clinical education of physiotherapy students in Australia: perceptions of current models. Australian Journal of Physiotherapy, 50(4), 243-247. doi:10.1016/S00049514(14)60114-8.

Strohschein, J., Hagler, P., \& May, L. (2002). Assessing the need for change in clinical education practices. Physical Therapy, 82(2), 160-172. doi:10.1093/ ptj/82.2.160.

Watson, K., Wright. A., Morris. N., McMeeken. J., Rivett, D., Blackstock, F., . Peterson R. (2012). Can simulation replace part of clinical time? Two parallel randomised controlled trials. Medical Education, 46,657-667. doi:10.1111/j.1365-2923.2012.04295.x.

Weller, J.M., Nestel, D., Marshall, S.D., Brooks PM., \& Conn, J.J. (2012). Simulation in clinical teaching and learning. Medical Journal of Australia, 196, 1-5. doi:10.5694/mja10.114744 


\section{Appendix 1}

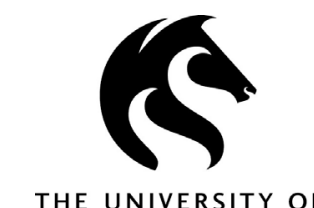

NEWCASTLE

AUSTRALIA

\section{Attitudes towards simulated learning experiences in physiotherapy clinical education Pre-simulation Student Survey}

Feedback about the student experience of simulated learning experiences in physiotherapy clinical education is very important. Thank you for completing the following survey about your combined simulation placement. Do not write your name on this survey however write your unique research code in the box below. This code will be given to you at the start of the placement.

\section{Research Code:}

\section{Section 1: Information about you.}

1. Which year of the physiotherapy program are you in?

$\square$ Year One $\square$ Year Two $\square$ Year Three $\square$ Year Four

2. What is your gender?

$\square$ Female $\square$ Male

3. How old are you? years

4. Have you undertaken tertiary study prior to entering the physiotherapy program?

$\square$ No Yes, please specify

5. Have you previously participated in simulation education using actors (standardised patients)?

$\square$ No $\square$ Yes

6. Have you previously participated in simulation education using mannequins (Dummies)?

$\square$ No $\square$ Yes

7. Was simulation one of your five placement preferences?

$\square$ No $\square$ Yes 


\section{Section 2: Attitudes towards simulated learning experiences}

1. Please place a cross or a tick in the box that best indicates whether you agree or disagree with the following statements.

\begin{tabular}{|c|c|c|c|c|c|}
\hline Simulated learning experiences... & $\begin{array}{l}\text { Strongly } \\
\text { disagree }\end{array}$ & Disagree & Neutral & Agree & $\begin{array}{l}\text { Strongly } \\
\text { agree }\end{array}$ \\
\hline Are valuable in physiotherapy clinical education & $\square$ & $\square$ & $\square$ & $\square$ & $\square$ \\
\hline $\begin{array}{l}\text { Are equivalent to traditional placement in the clinical } \\
\text { setting }\end{array}$ & $\square$ & $\square$ & $\square$ & $\square$ & $\square$ \\
\hline $\begin{array}{l}\text { Are useful in preparation of students for clinical } \\
\text { placement }\end{array}$ & $\square$ & $\square$ & $\square$ & $\square$ & $\square$ \\
\hline $\begin{array}{l}\text { Help to develop student confidence for clinical } \\
\text { placement }\end{array}$ & $\square$ & $\square$ & $\square$ & $\square$ & $\square$ \\
\hline Are not realistic & $\square$ & $\square$ & $\square$ & $\square$ & $\square$ \\
\hline $\begin{array}{l}\text { Are a waste of time that I could be spending in the } \\
\text { clinical setting }\end{array}$ & $\square$ & $\square$ & $\square$ & $\square$ & $\square$ \\
\hline Assist students to develop professional behaviour & $\square$ & $\square$ & $\square$ & $\square$ & - \\
\hline $\begin{array}{l}\text { Assist students to develop confidence and skills in } \\
\text { communicating with patients }\end{array}$ & $\square$ & $\square$ & $\square$ & $\square$ & ${ }^{-}$ \\
\hline $\begin{array}{l}\text { Assist students to develop knowledge and skills in } \\
\text { gathering medical information }\end{array}$ & $\square$ & $\square$ & $\square$ & $\square$ & $\square$ \\
\hline Assist students to develop subjective assessment skills & $\square$ & $\square$ & $\square$ & $\square$ & \begin{tabular}{|c} 
\\
\end{tabular} \\
\hline Assist students to develop physical assessment skills & $\square$ & $\square$ & $\square$ & $\square$ & $\square$ \\
\hline Assist students to develop their clinical reasoning & $\square$ & $\square$ & $\square$ & $\square$ & $\square$ \\
\hline Assist students to develop manual handling skills & $\square$ & $\square$ & $\square$ & $\square$ & $\square$ \\
\hline $\begin{array}{l}\text { Assist students to develop confidence and skills in } \\
\text { performing practical treatment techniques }\end{array}$ & $\square$ & $\square$ & $\square$ & $\square$ & $\square$ \\
\hline
\end{tabular}

2. Do you have any other comments about your perceptions or attitudes towards simulated learning experiences (SLE) in physiotherapy clinical education 